\title{
Experimental study on dynamic effect of freestanding tower of sea-crossing bridge under wave load
}

\author{
Zhou Daocheng $^{1^{*}}$, Zhang Bo ${ }^{1}$, Xue Sisi ${ }^{1}$, Wei Chengxun ${ }^{2^{*}}$ and Ou Jinping ${ }^{3}$
}

\author{
*Correspondence: zhoudc@dult. \\ edu.cn; weichengxun@163.com \\ 'Deepwater Engineering Research \\ Center, Dalian University of \\ Technology, Dalian 116024, China \\ ${ }^{2}$ School of Civil Engineering and \\ Architecture, Guangxi University of \\ Science and Technology, Liuzhou \\ 545006, China \\ Full list of author information is \\ available at the end of the article
}

\begin{abstract}
There is a debate over whether the sea-crossing bridges undergo dynamic motions when exposed to wave loads. In order to verify the dynamic effect of the tower of sea-crossing bridge under wave load, an experimental study on dynamic effect of a freestanding tower of sea-crossing bridge is accomplished in this paper. Firstly, a test model for a typical bridge tower of pile group foundation under wave load is established by using a scale of 1:100. Secondly, a typical sea condition is designed for the response test of the bridge tower under wave load. The test results indicated that obvious vibration of top the tower occurs when the wave load period is close to the natural vibration period of the structure, and both displacement and base shear are amplified. The results in this paper will provide an important reference for whether the dynamic effect of wave load should be considered in the designs of bridge structure under wave load.

Keywords: Tower of sea-crossing bridge, Wave load, Base shear, Dynamic effect
\end{abstract}

\section{Springer Open}

\section{Introduction}

In the twenty-first century, with the increasingly closer communication between continents, countries and islands during the economic globalization, large-scale sea-crossing projects have been conducted rapidly to establish the connecting network. At present, the famous sea-crossing bridges completed include: Japan Akashi Strait Bridge, Hong Kong Stonecutters Bridge, Indonesia Surabaya Madura Bridge, Hong Kong-ZhuhaiMacao Bridge, Hangzhou Bay Bridge, etc. The sea-crossing bridge are often subjected to strong winds and waves. Therefore, it is very important to ensure the safety of the bridge structure in the process of construction and service.

More and more attention have been paid to the marine environmental conditions and their effects by scholars at home and abroad, especially a series of studies on wind and wave environmental conditions and their effects. The upper bridge panel structure is more likely to be damaged under wave load, which can be traced back to the research on wave forces of flat plates and offshore platforms in the 1990s (Shih and Anastasiou 1992; Kaplan et al. 1995). Douglass et al. (2006) proposed an empirical formula

(c) The Author(s). 2021 Open Access This article is licensed under a Creative Commons Attribution 4.0 International License, which permits use, sharing, adaptation, distribution and reproduction in any medium or format, as long as you give appropriate credit to the original author(s) and the source, provide a link to the Creative Commons licence, and indicate if changes were made. The images or other third party material in this article are included in the article's Creative Commons licence, unless indicated otherwise in a credit line to the material. If material is not included in the article's Creative Commons licence and your intended use is not permitted by statutory regulation or exceeds the permitted use, you will need to obtain permission directly from the copyright holder. To view a copy of this licence, visit http://creativecommons.org/licenses/by/4.0/. 
for estimating the extreme wave forces on slab superstructure by studying bridges damaged in hurricane. Huang et al. (2018) built a two-dimensional numerical wave tank based on the OpenFOAM program to study the impact and breaking of wave action on the structure, and analyze the stress mechanism. Guo et al. (2015) carried out hydrodynamic experiment of the extreme wave forces on the superstructure of coastal highway bridges, and proposed an estimation formula for calculating the extreme wave forces on such bridges. Lotfollahi-Yaghin et al. (2012) established the relationship between wave force and liquid level fluctuation around vertical cylinder by using artificial neural network model, which was used for rapid prediction of wave load. Wei et al. (2017) obtained the variation characteristics between the structural response and load parameters by conducting experimental research on the structural response of independent bridge towers under the action of wave-current load. Bai et al. (2016) and Guo et al. (2016) conducted an experimental study on the structural response of independent bridge towers under wind-wave loads, and obtained their response rules. Liu et al. (2017) used numerical method to analyze the random vibration of sea-crossing bridge under wind-wave load. Liu et al. (2015) carried out experimental study on structural response of independent bridge tower under win-wave-current load, and obtained its response variation rules. Chengxun (2018) systematically studied the dynamic response of cable-stayed bridges across the sea under the combined action of wind, wave and current. Bonakdar et al. (2015) and Bonakdar and Oumeraci (2012) systematically studied the pile group coefficient of pile group foundations with different arrangement, and summarized a series of empirical formulas. These studies mainly focus on the study of wave load and its response and pile group effect coefficient, but some of them also found that the bridge tower will vibrate when the frequency of wave acting on the bridge tower is close to the natural frequency of the bridge tower (Liu et al. 2015; Chengxun 2018), which is different from the conventional understanding: there is no vibration in the tower structure. The reasons are the stiffness of the tower is very high and the action position of the wave load is inclined to the bottom of the bridge tower.

The structural response characteristics of sea-crossing bridges under wave loads must be obtained for the reasonable structural design. Therefore, a physical model of bridge tower was established based on a large sea-spanning cable-stayed bridge. An experimental study on the response of the bridge tower under the typical conditions of wave load is conducted. The dynamic response characteristics and action mechanism is discussed. These works provides a reference for the bridge design to consider the wave load reasonably.

\section{Description of the bridge tower and physical model design}

The bridge tower served as the prototype structure for the experiment is a component of a planned sea-crossing bridge of the Qiongzhou Strait of China. The foundation of the tower is designed to be a pile-group foundation. The tower is designed to be a double-column, gate-type structure, as Fig. 1 shows. The height of the tower is 203.95 $\mathrm{m}$ from the top of the pile cap to the tower top. The pile-group is composed of 16 piles. Each pile is $3 \mathrm{~m}$ in diameter and $23 \mathrm{~m}$ in length from the seabed to the bottom of the pile cap. The cross sections and the main design sizes of the foundation, tower columns and crossbeams are shown in Fig. 1c. 


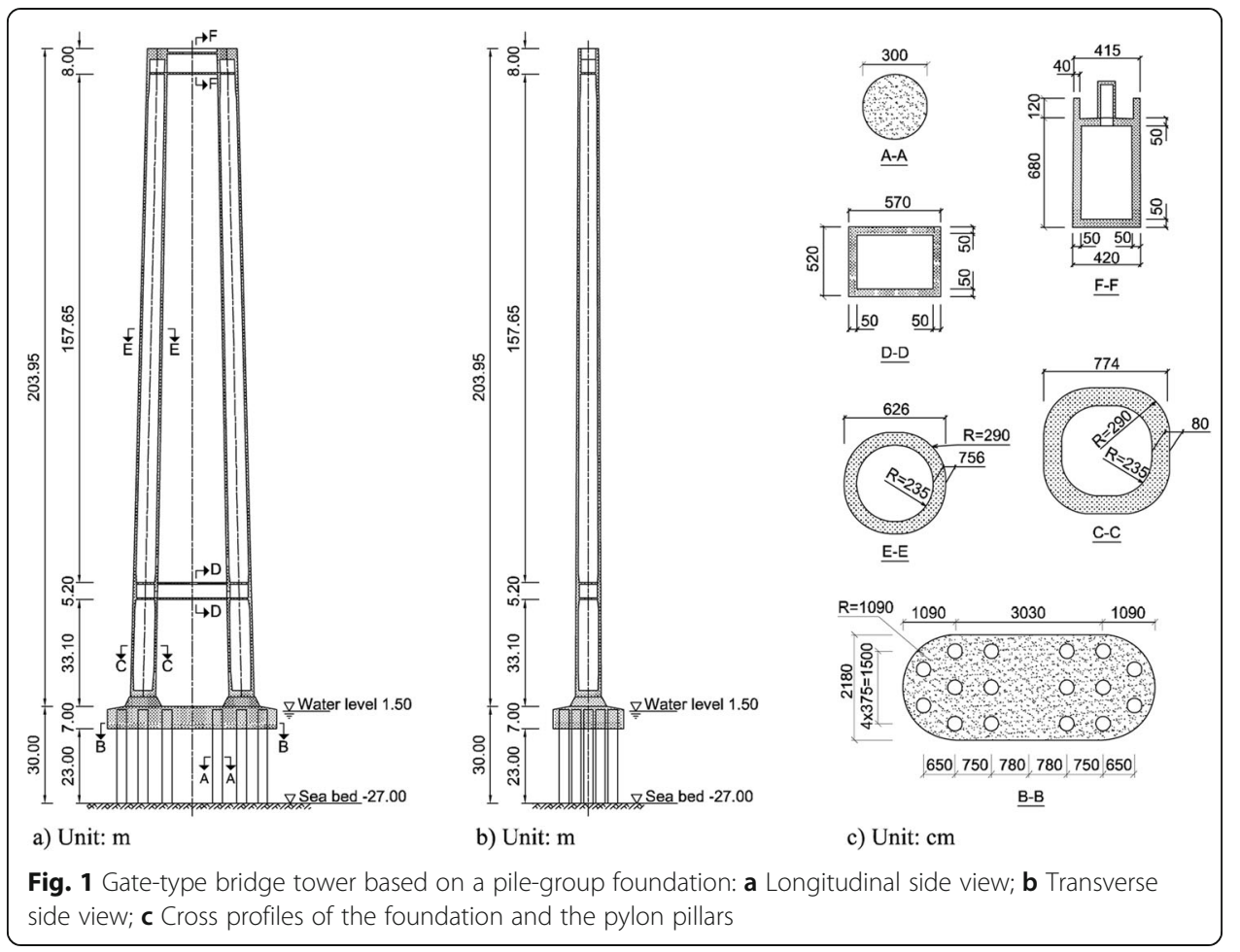

The experiment model was made with a geometric scale of 1:100 with consideration of the experimental contents and the conditions of the experimental facilities. Geometric similarity, Froude similarity and elastic-gravity similarity criterions were used to design the model (Chi and Lin 2004). Geometric similarity is to ensure the length, width and height of the structure model and the water depth, wave length and wave height of the flume wave to have a same geometric scale. As the gravity and inertia forces of fluid are the main determinants of the wave on a bridge structure. The flow field of flume wave was designed to satisfy the Froude similarity, that is

$$
\frac{\lambda_{g} \lambda_{l}}{\lambda_{v}^{2}}=1, \frac{\lambda_{l}}{\lambda_{t} \lambda_{v}}=1
$$

Where $\lambda_{l}, \lambda_{g}, \lambda_{v}$ and $\lambda_{t}$ are geometric scale, gravity scale, velocity scale and time scale respectively. The structure model of the tower was designed to satisfy the elasticgravity similarity. The similarity relation is.

$$
\lambda_{E}=\lambda_{l} \lambda_{\rho}, \quad \lambda_{t}=\lambda_{l}^{1 / 2}
$$

Where $\lambda_{E}$ and $\lambda_{\rho}$ are elasticity modulus scale and density scale respectively.

Being an elastic dynamic structure, the model consists of the skeleton, clump weights, and polyethylene shells, as Fig. 2a shows. The skeleton was welded by 16 circular iron bars that served as the pile group, a steel plate that served as the pile cap, two long circular iron bars that served as the tower columns and two rectangular iron bars that served as the crossbeams. The cross-section dimensions of the iron bars were determined by the flexural stiffness of the cross sections of the corresponding components on the prototype structure. The skeleton is design to simulate the overall flexural stiffness of the bridge tower and is the main stress component of the model. To satisfy the 


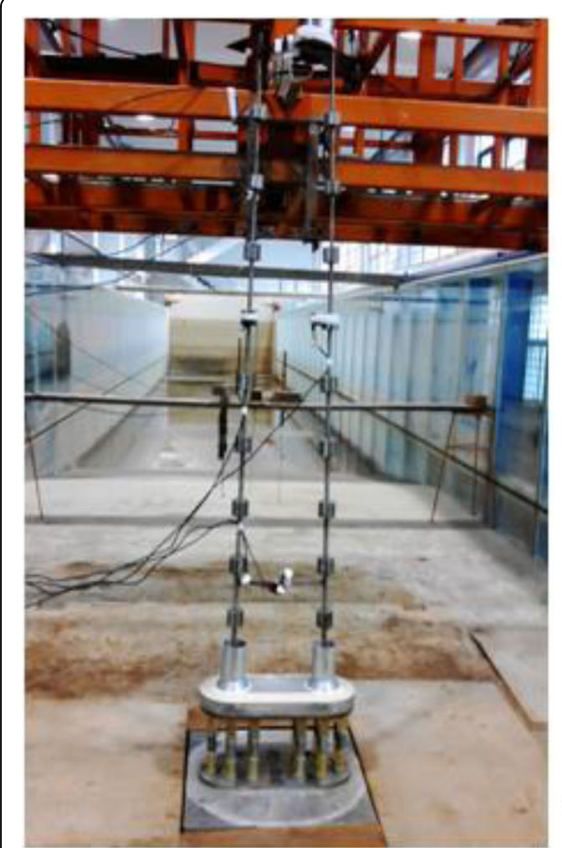

(a)

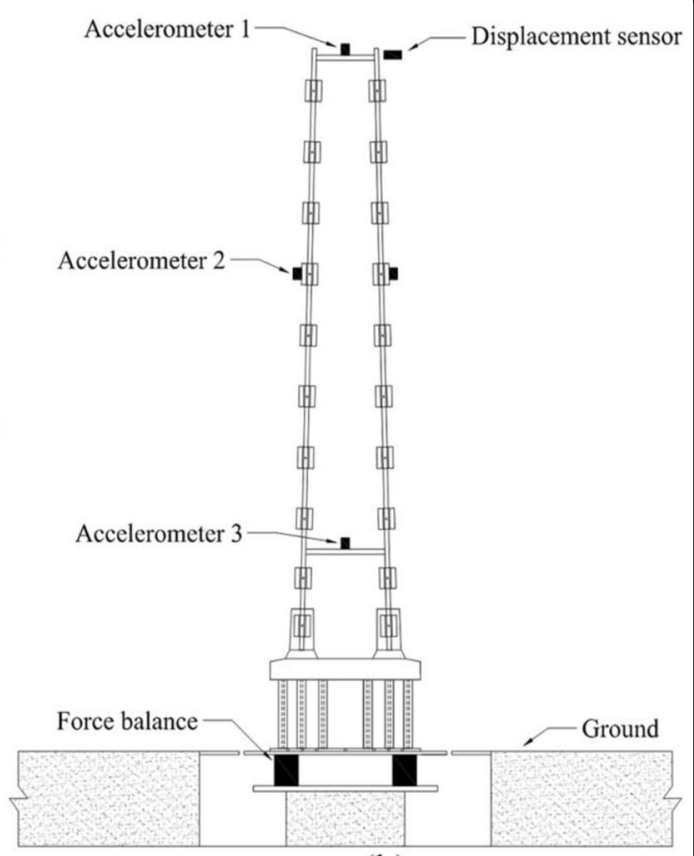

(b)

Fig. 2 Model structure and experimental setup of the gate-type bridge tower: a Model construction and the sensor placements; $\mathbf{b}$ Picture of the model in the flume

gravity similarity, iron clump weights were fixed on the tower columns of the model. Under wave actions, the surface of the underwater part of the prototype tower would be simulated by the model. Therefore, some polyethylene shells were pasted on the underwater part of the model to satisfy its geometric similarity.

\section{Model test and measurement}

\subsection{Test equipment and measuring instrument}

The experiment was carried out at the State Key Laboratory of Coastal and Offshore Engineering, Dalian University of Technology, China. The wave flume used for the experiment possesses the capability of simulating waves As shown in Fig. 3, it is $60 \mathrm{~m}$ in length, $4 \mathrm{~m}$ in width and $2.5 \mathrm{~m}$ in height. Flume waves are generated by a piston-type wave maker at one side of the flume and absorbed by an absorber at the other side of the flume. The test model was located at the middle zone of the flume with a distance of $30 \mathrm{~m}$ from the wave maker. The incident wave recorded by a capacitance-type wave gauge and an acoustic Doppler velocimetry (ADV) placed at upstream of the model. Before the model tests were carried out, the flume waves were carefully calibrated to ensure their target values.

The layout of the measuring instruments for recording the dynamic responses of the model are shown in Fig. 1. Three two-component accelerometers were installed at three elevations on the model to measure the acceleration responses in the $x$ - and $y$-directions. Laser displacement sensors were installed on the traversing carriage above the flume to record the displacements of the tower top. The model was freestanding with its foundation fixed on an assembled force balance. The assembled force balance shown in Fig. 4. Then the wave induced base shear forces in $x$ - and $y$-directions would be measured by this force balance. 


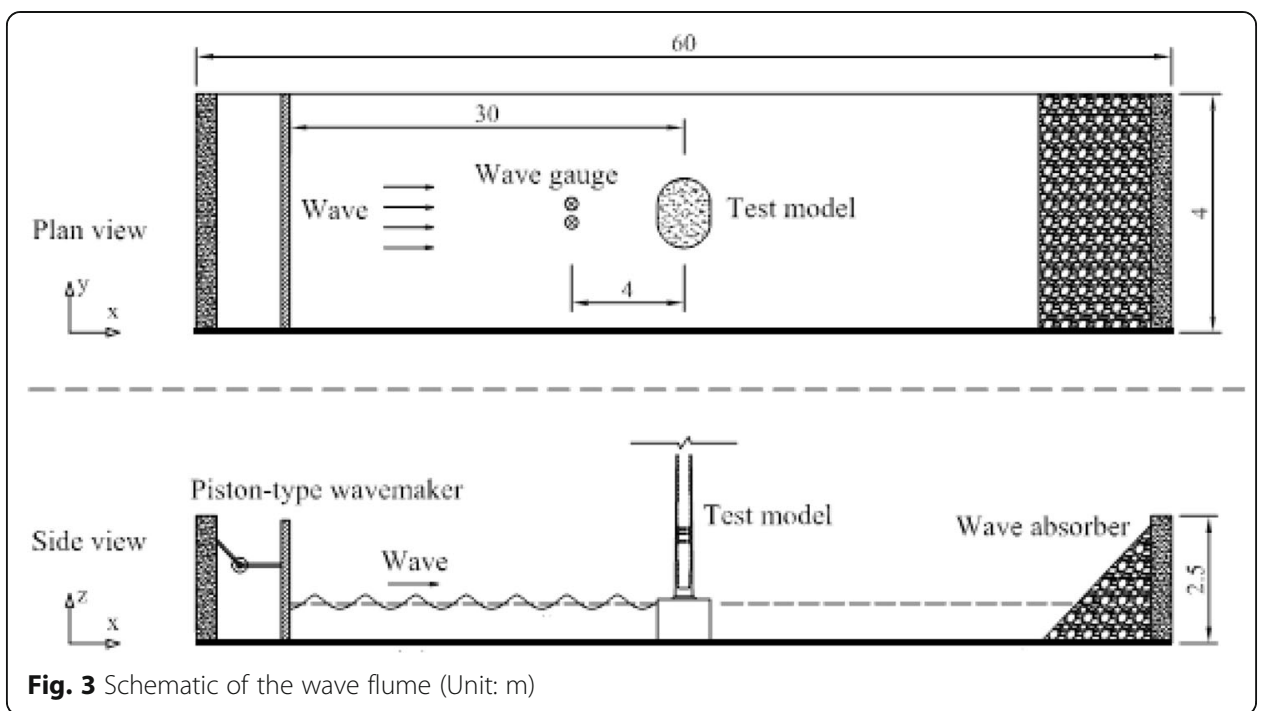

\subsection{Test conditions}

Load cases for the experiment were designed according to the sea state. A flume water depth of $28.5 \mathrm{~cm}$, which is corresponding to the designed water depth of $28.5 \mathrm{~m}$ shown in Fig. 1, was considered during the whole experiment. The hydrological data at the bridge site shows that the wave heights with a cumulative probability of $1 \%, H_{1 \%}$, for 25 -year and 100 year return periods are $3.0 \mathrm{~m}$ and $4.7 \mathrm{~m}$, respectively, and the corresponding average wave periods, $\bar{T}$, are $7.0 \mathrm{~s}$ and $9.6 \mathrm{~s}$, respectively. Additionally, with the resonant period of the structure focused on, the wave period of $7.8 \mathrm{~s}$ was also considered for the experiment. According to the geometric scale of 1:100 and the Froude similarity, six regular waves were determined for the experiment. Including the wave heights, $H$, wave periods, $T$, and water depth, $d$, The model and prototype parameters of these six load cases are listed in Table 1.

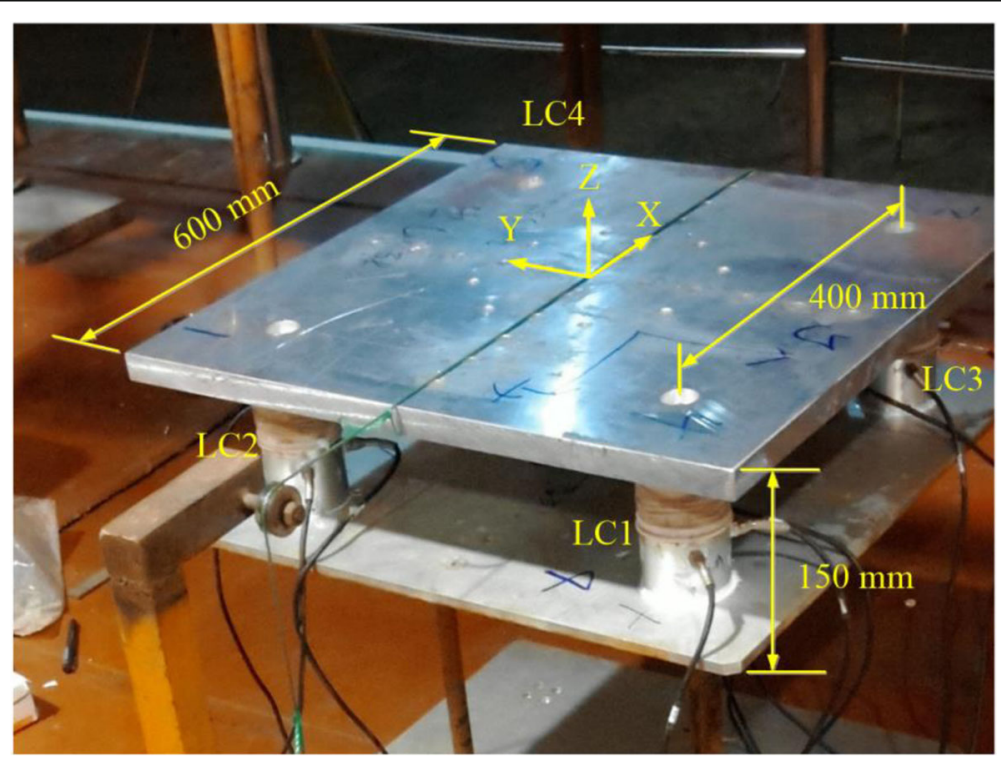

Fig. 4 Measuring instruments of the assembled force balance 
Table 1 Regular wave conditions of the tower test

\begin{tabular}{|c|c|c|c|c|c|c|}
\hline \multirow{2}{*}{$\begin{array}{l}\text { Working } \\
\text { condition }\end{array}$} & \multicolumn{3}{|c|}{ Scale values } & \multicolumn{3}{|c|}{ Prototype value } \\
\hline & $H(\mathrm{~cm})$ & $T(\mathrm{~s})$ & $d(\mathrm{~cm})$ & $H(\mathrm{~m})$ & $T(\mathrm{~s})$ & $d(\mathrm{~m})$ \\
\hline W1 & 3.0 & 0.70 & 28.5 & 3.0 & 7.0 & 28.5 \\
\hline W2 & 4.7 & 0.70 & 28.5 & 4.7 & 7.0 & 28.5 \\
\hline W3 & 3.0 & 0.78 & 28.5 & 3.0 & 7.8 & 28.5 \\
\hline W4 & 4.7 & 0.78 & 28.5 & 4.7 & 7.8 & 28.5 \\
\hline W5 & 3.0 & 0.96 & 28.5 & 3.0 & 9.6 & 28.5 \\
\hline W6 & 4.7 & 0.96 & 28.5 & 4.7 & 9.6 & 28.5 \\
\hline
\end{tabular}

\subsection{Model test and measurement}

In the test, the structural model was fixed on the force balance by bolts, and the force balance was fixed in the reserved hole at the bottom of the flume. The model installation diagram is shown in Fig. 2. After the model is installed, the measuring sensors are installed and measurement system is built. Install measurement sensor and build measurement system. The synchronous acquisition of wave time history, force, acceleration and displacement should be considered in the test.

\section{Experimental results and discussion}

\subsection{Dynamic characteristic analysis of the bridge tower}

Before testing the dynamic responses of the model under the flume wave actions, freedecay tests was conducted with and without water to find out the dynamic characteristics of the structure. According to the measuring acceleration and displacement records, the natural vibration frequencies of the model structure are obtained, and the results are listed in Table 2. The free decay displacement and acceleration of the top of the tower are recorded as shown in Fig. 5.

The modal analysis was carried out on the finite element model of the prototype tower. The first two natural frequencies of the structure were listed in Table 2, and the corresponding flexural deformations along $\mathrm{x}$ - and $\mathrm{y}$-directions are the main mode shapes of the structure, as Table 2 shows. They are corresponding to the first two natural frequencies of the structure. According to the results shown in Fig. 6, the first two modes of the structure are bending deformation along the $\mathrm{x}$ and $\mathrm{y}$ directions respectively, mainly because the pile foundation of the bridge tower is rigid, and the bridge tower is equivalent to a cantilever beam, so the bending deformation is mainly. Due to the large stiffness of the pile foundation of the bridge tower, the pile foundation is basically motionless during the test, so the frequency of the structure with and without water is basically the same. The calculated frequency of the bridge tower is basically consistent with the frequency obtained from the test, which indicates that the structural physical test model is designed reasonably.

Table 2 Natural frequencies of the gate-type bridge tower

\begin{tabular}{|c|c|c|c|c|}
\hline \multirow{2}{*}{$\begin{array}{l}\text { Direction of } \\
\text { vibration mode }\end{array}$} & \multicolumn{2}{|c|}{ Calculated frequency $(\mathrm{Hz})$} & \multicolumn{2}{|c|}{ Test frequency $(\mathrm{Hz})$} \\
\hline & Prototype value & Model values & Without water & With water \\
\hline Along the bridge & 0.124 & 1.241 & 1.277 & 1.268 \\
\hline Cross the bridge & 0.260 & 2.670 & 2.830 & 2.808 \\
\hline
\end{tabular}



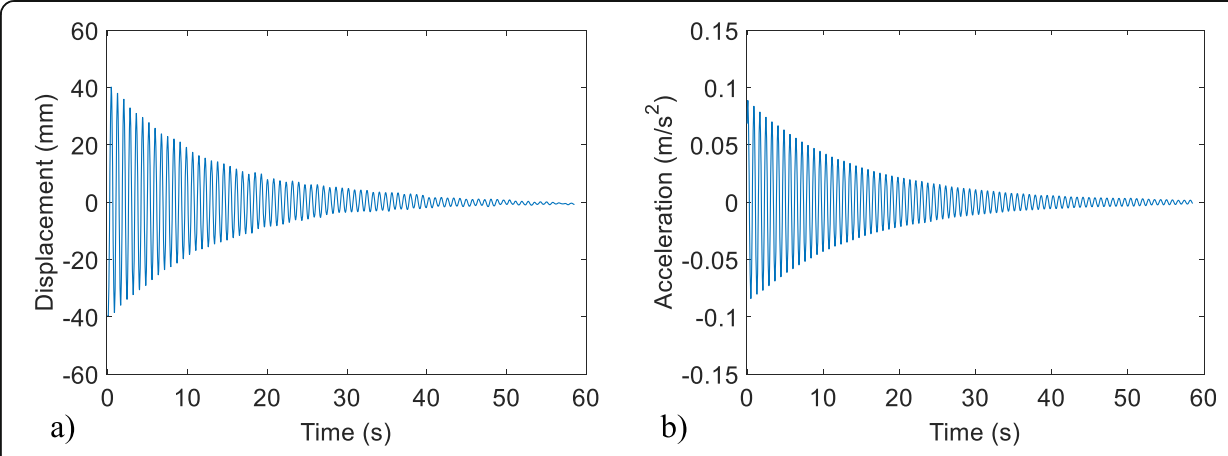

Fig. 5 Displacement and acceleration records of the decay test of the gate-type bridge tower model structure (longitudinal oscillation, without water)

\subsection{Analysis for base shear forces of the bridge tower}

The peak value and the valley value of the shear force at the base of the bridge represent the positive force and the negative force of the pile. During the test, it was found that the peak value and the valley value of the base shear forces on the bridge foundation were asymmetric, and the peak value was generally greater than the valley value. Considering the safety of the structure, the peak force was used for statistical analysis. According to the measurement results of the force balance, the measured shear forces on the base of the bridge foundation was sorted out, and the shear forces on the base of the prototype bridge under each test condition was obtained. The sorted results were listed in the Table 3, some of which were shown in Fig. 7.

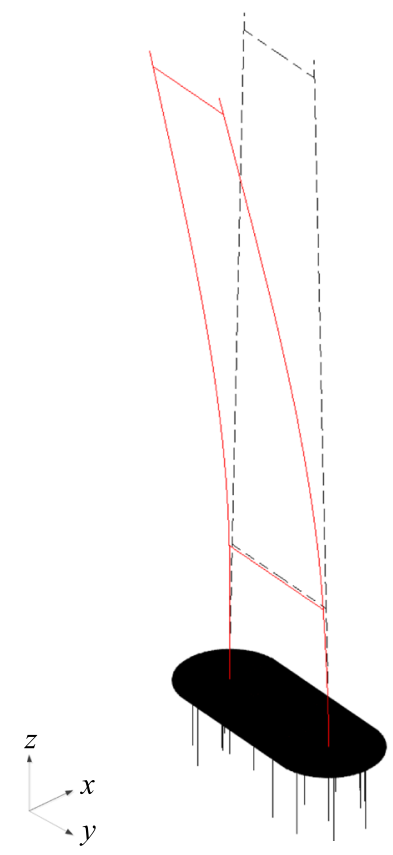

a)

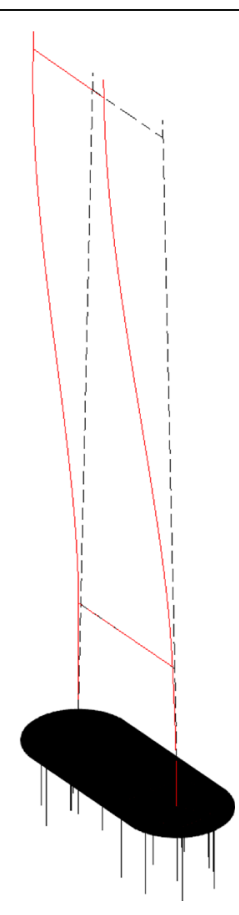

b)

Fig. 6 Mode shapes of the gate-type bridge tower: a The first-order longitudinal mode shape; $\mathbf{b}$ The second-order transverse mode shape 
Table 3 Base shears of the prototype bridge tower $\left(10^{3} \mathrm{KN}\right)$

\begin{tabular}{llll}
\hline $\begin{array}{l}\text { Wave } \\
\text { height } \\
(\mathbf{m})\end{array}$ & Period (s) & $\mathbf{7 . 8}$ & $\mathbf{9 . 6}$ \\
\cline { 2 - 4 } & $\mathbf{7}$ & 7.5071 & 5.9687 \\
\hline 3.0 & 8.1505 & 12.6141 & 10.8178 \\
\hline .7 & 11.2266 & & \\
\hline
\end{tabular}

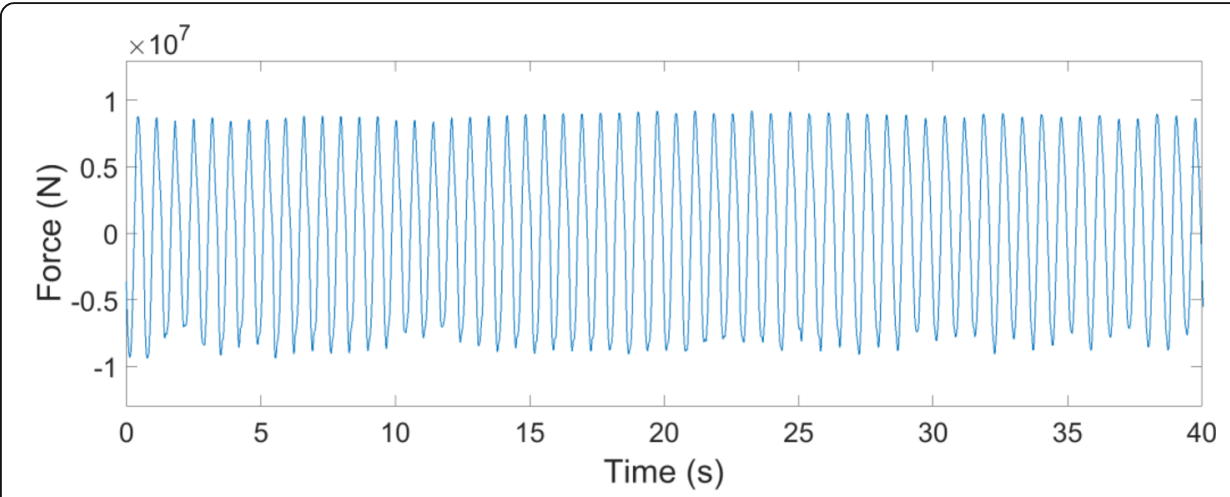

(a) $\mathrm{H}=3 \mathrm{~m}, \mathrm{~T}=7 \mathrm{~s}$

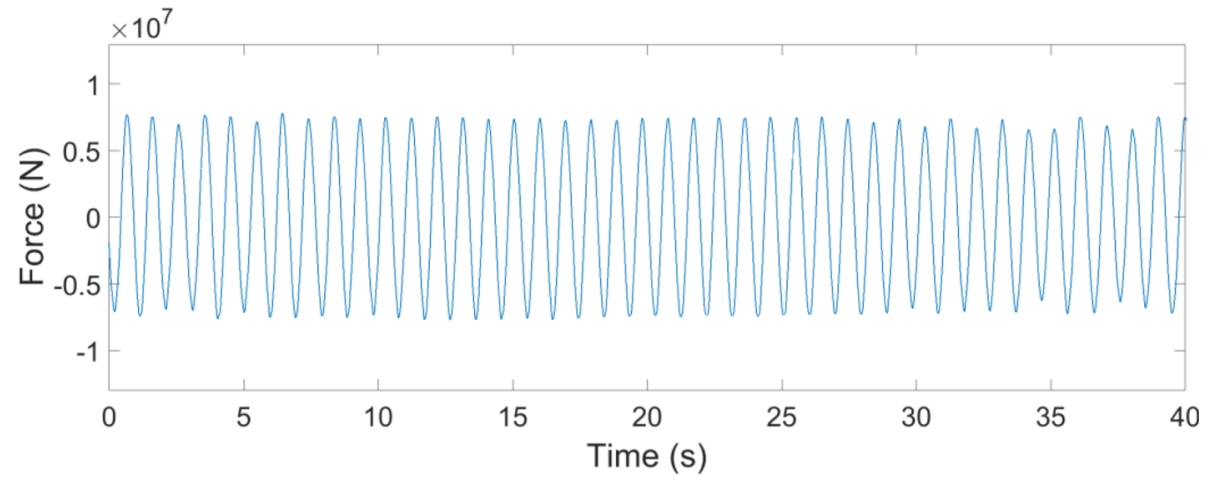

(b) $\mathrm{H}=3 \mathrm{~m}, \mathrm{~T}=7.8 \mathrm{~s}$

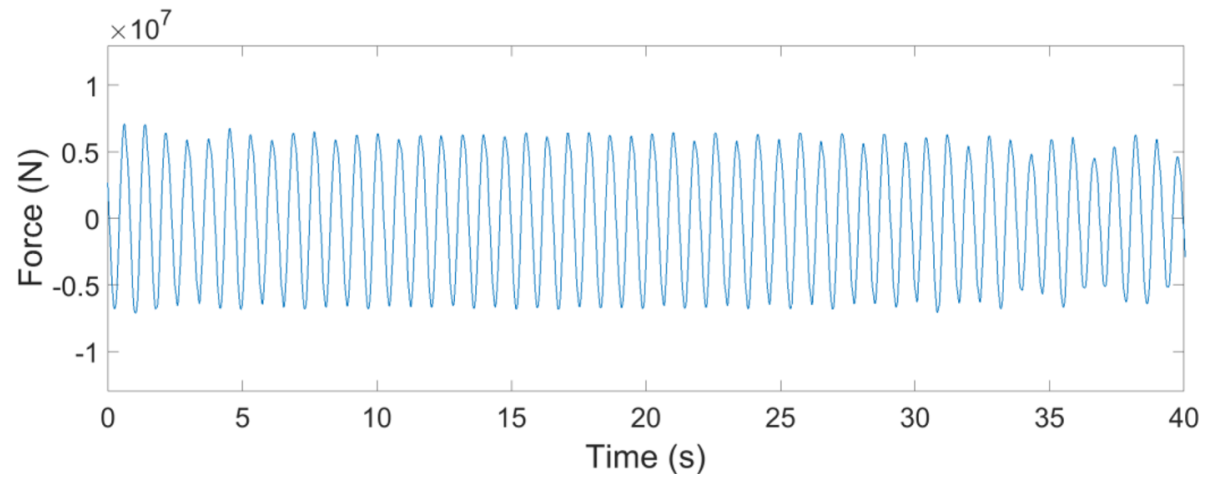

(b) $\mathrm{H}=3 \mathrm{~m}, \mathrm{~T}=9.6 \mathrm{~s}$

Fig. 7 Variation characteristics of base shear forces of bridge tower with time 
Table 4 Top displacement of the prototype bridge tower (m)

\begin{tabular}{llll}
\hline $\begin{array}{l}\text { Wave } \\
\text { height } \\
(\mathbf{m})\end{array}$ & Period (s) & $\mathbf{7 . 8}$ & $\mathbf{9 . 6}$ \\
\cline { 2 - 4 } & $\mathbf{7}$ & 0.276 & 0.005 \\
\hline 3.0 & 0.036 & 0.417 & 0.007 \\
4.7 & 0.050 & & \\
\hline
\end{tabular}

According to the results in Table 3, when the wave height is $3 \mathrm{~m}$, the shear forces at the base of the bridge decreases with the wave period increasing. When the wave height is $4.7 \mathrm{~m}$, the base shear forces of the bridge foundation changes with the wave period, which first increases and then decreases with the change of the period. Except for the difference in wave height, their changing laws should be consistent under the same conditions. The cause of this inconsistency is likely to be that the wave period of $7.8 \mathrm{~s}$ approximates to the main period of the structure. Structure vibration produces dynamic amplification effect, and structure dynamic effect of the wave height of $4.7 \mathrm{~m}$ is higher than the wave height of $3 \mathrm{~m}$, that can be verified by the vertex displacement of the structure from the Table 4 . The displacement of the top structure when the wave height is $4.7 \mathrm{~m}$ is 1.51 times the displacement of the top structure when the wave height is $3 \mathrm{~m}$. The reason is likely to be that the shear forces at the base of the bridge with the wave height of $4.7 \mathrm{~m}$ is higher than the wave height of $3 \mathrm{~m}$, and the shear with the wave height of $4.7 \mathrm{~m}$ is 1.68 times the shear with the wave height of $3 \mathrm{~m}$ in Table 3.

\subsection{Analysis for top displacement of the bridge tower}

According to the measured results of the laser displacement meter, the measured top displacement of the bridge tower was sorted out, and the top displacement of the prototype bridge tower in each test condition was obtained. The sorted results were listed in Table 4, and some of the results were shown in Fig. 8.

According to Fig. 8, when the wave period is $7.8 \mathrm{~s}$, the top part of the bridge tower vibrates significantly, showing an obvious dynamic amplification effect. This is because the wave period is consistent with the main period of the structure, and the structure has resonance effect. According to the results in Table 4, the peak displacement of the structure when the wave height is $4.7 \mathrm{~m}$ is significantly larger than that when the wave

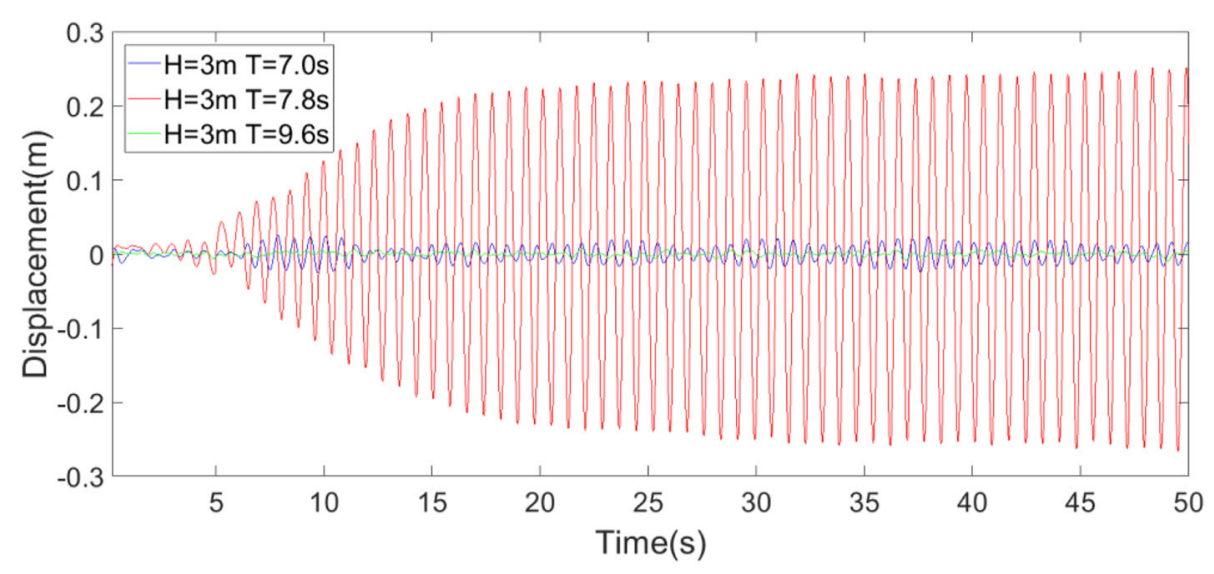

Fig. 8 Variation characteristics of top displacement of bridge tower with time 
height is $3 \mathrm{~m}$. This is mainly because the higher the wave height is, the greater the wave load is. Even if the amplification coefficient of the structure dynamic response is consistent, the dynamic response of the structure is also larger.

\section{Conclusion}

In this paper, the dynamic effect of the tower structure under wave load is studied through physical model test, and the main conclusions are as follows:

(1) The first two frequencies calculated by the bridge tower structure are basically consistent with the first two frequencies measured by the test, which indicates the rationality of the design and manufacture of the physical test model of bridge tower and is the premise to ensure the reasonableness of the test results.

(2) Under the condition that the wave period is consistent with the structural period, the wave load can cause the dynamic effect of the bridge tower structure, and the higher the wave height, the more obvious the dynamic amplification effect of the base shear forces and the displacement of bridge tower structure. How to calculate the amplification effect of the base shear forces and the displacement needs to be further studied.

\section{Acknowledgements}

The State Key Laboratory of Coastal and Offshore Engineering of Dalian University of Technology are gratefully acknowledged.

\section{Authors' contributions}

ZDC conceived of the study, and participated in its design and coordination and helped to draft the manuscript. ZB participated out the experiment studies and drafted the partial manuscript. XSS participated the experiment studies and drafted the partial manuscript. WCX carried out the experiment studies and analysis of test data. OJP given general guidance and advice. All authors read and approved the final manuscript.

\section{Funding}

This work was supported by the Technology Project of the Ministry of Transport of China (Grant Number 2011318494150).

Availability of data and materials

All data and materials in their manuscript can be applied publicly.

\section{Competing interests}

The author(s) declared no potential conflicts of interest with respect to the research, authorship, and/or publication of this article.

\section{Author details}

1Deepwater Engineering Research Center, Dalian University of Technology, Dalian 116024, China. ${ }^{2}$ School of Civil Engineering and Architecture, Guangxi University of Science and Technology, Liuzhou 545006, China. ${ }^{3}$ School of Civil Engineering, Dalian University of Technology, Dalian 116024, China.

Received: 26 November 2020 Accepted: 30 December 2020

Published online: 16 March 2021

\section{References}

Bai XD, Guo AX, Liu H et al (2016) Experimental investigation on a freestanding bridge tower under wind and wave loads. Struct Eng Mech 57(5):951-968

Bonakdar L, Oumeraci H (2012) Interaction of waves and pile group - supported offshore structures: a large scale model study. International Society of Offshore and Polar Engineers

Bonakdar L, Oumeraci H, Etemad-Shahidi A (2015) Wave load for prediction of wave-induced forces on a slender pile within pile groups. Coast Eng 102:49-68

Chengxun W (2018) Wind, wave and current joint actions and dynamic responses of long span sea--crossing cable--stayed bridges. Doctoral dissertation, Dalian University of Technology.

Chi S, Lin S (2004) Validation of similitude laws for dynamic structural model test. World Earthq Eng 12(4):11-20

Douglass SL, Chen Q, Olsen JM et al (2006) Wave forces on bridge decks. U.S. Department of Transportation Federal Highway Administration, Washington, DC

Guo AX, Fang QH, Bai XD et al (2015) Hydrodynamic experiment of the wave force acting on the superstructures of coastal bridges. J Bridge Eng 20(12):04015012 
Guo AX, Liu JB, Chen WL et al (2016) Experimental study on the dynamic responses of a freestanding bridge tower subjected to coupled actions of wind and wave loads. J Wind Eng Ind Aerodyn 159:36-47

Huang B, Zhu B, Cui SG et al (2018) Experimental and numerical modelling of wave forces on coastal bridge superstructures with box girders, Part I: regular waves. Ocean Eng 149:53-77

Kaplan K, Murray JJ, Yu WC (1995) Theoretical analysis of wave impact forces on platform deck structures. In: Proceedings of the 14th international conference on offshore mechanics and arctic engineering, vol 1A. ASME, Copenhagen, pp 189198

Liu G, Chen SY, Liu TC et al (2017) An analysis method for wind-wave coupling induced random vibration of sea-crossing super-large bridges. Appl Math Mech 38(1):75-89

Liu HY, Geng BL et al (2015) Experimental study on elastic model of bridge tower under wind, wave and current. J Waterw Harb 36(6):461-466

Lotfollahi-Yaghin MA, Pourtaghi A, Sanaaty B et al (2012) Artificial neural network ability in evaluation of random waveinduced inline force on a vertical cylinder. China Ocean Eng 26(1):19-36

Shih RWK, Anastasiou K (1992) Wave induced uplift on a horizontal platform. Water Marit Energy 96(1):19-33

Wei CX, Zhou DC, Ou JP (2017) Experimental study of the hydrodynamic responses of a bridge tower to waves and wave currents. J Waterw Port Coastal Ocean Eng 143(3):04017002

\section{Publisher's Note}

Springer Nature remains neutral with regard to jurisdictional claims in published maps and institutional affiliations.

Submit your manuscript to a SpringerOpen ${ }^{\circ}$ journal and benefit from:

- Convenient online submission

- Rigorous peer review

- Open access: articles freely available online

- High visibility within the field

- Retaining the copyright to your article

Submit your next manuscript at $\boldsymbol{\nabla}$ springeropen.com 